Background The Japan Paediatric Society is currently surveying information management strategies at other societies in order to gain insight for the future development of their own information management strategy. To this end, we conducted a survey of personal information management strategies upon admission to subcommittees of the Japan Paediatric Society as a pilot study.

Objective The present study aimed to clarify the state of personal information management upon admission to Japan Paediatric Society subcommittees in order to determine information management strategies in the future.

Methods The contract terms for physicians upon admission to Japan Paediatric Society subcommittees were examined based on subcommittee websites.

Results Of the 23 subcommittees, 21 had websites, and one did not have a working URL to the website (as of April 4, 2014). Moreover, one subcommittee did not have information pertaining to admission on its website. Accordingly, we surveyed the 19 subcommittees which had websites that could be analysed. Information provided by the subcommittee websites included the following: basic information regarding how personal information is handled, 3; recommendation required, 5; name, 19 (furigana, 16; English 6), gender, 15; birthdate, 17; home address, 19; home phone (fax), 19; e-mail address, 18; workplace, 19; work address, 19; work phone number, 19; specialty, 10; and highest academic degree, 5 .

Conclusion From the perspective of information management, the Japan Paediatric Society must maintain close collaboration with the various subcommittees in the future.

\section{PO-0952 NEONATAL RESUSCITATION OPTION IN ISLAM}

B Kurdi. NICU, Hamad General Hospital, Doha, Qatar

\subsection{6/archdischild-2014-307384.1573}

Background A Do Not Resuscitate (DNR) order would be similar to many of the decisions a physician faces daily if it did not call for ethical and legal considerations. To comply with the intent of the order, a physician must be certain that further resuscitation is futile and is a waste of resources.

Method We offer both ways of DNR for parent of 25 cases in the last 12 months (10 cases were extrem preterm 23 weeks with bilateral IVH grad 4, and 4 cases were trisomy 18 with congenital anomalise, and 7 cases with sever form of multiple conginetal, 4 cases of inoperable complex congenital heart disease).

Results After we explain to the parents about the prognosis of those cases, 12 of them agreed to not be aggressive in the resuscition if the condition of the patient deteriorated, and 2 of them agreed to withdraw the therapy.

Conclusion The majority of scholars said that the treatment of patients is desirable (not a must) where there is a hope of recovery, and DNR order is Permitted (mobah) in cases of a high degree of certainty that resuscitation is futile to the Patient, but does not mean to stop the fundamental support like antibiotic, feeding, and IV fluid. The treatment is mandatory (sever paintreatment is successful-infectious diseases that will spread to others) While the intentional interference of the doctor by giving the patient medication to hasten the death in some cases which is called Euthanasia It is absolutely forbidden in Islam.

\section{PO-0953 WITHDRAWN}

\section{PO-0954 CLICK! ENGAGING CHILDREN IN RESEARCH ABOUT THEIR LIVES: EXPERIENCES OF USING PHOTO-ELICITATION FROM ENGLAND, AUSTRALIA AND NEW ZEALAND}

${ }^{1} \mathrm{~B}$ Carter, ${ }^{2} \mathrm{~K}$ Ford, ${ }^{3} \mathrm{~A}$ Dickinson, ${ }^{4} \mathrm{~L}$ Bray, ${ }^{3} \mathrm{~T}$ Water, ${ }^{1} \mathrm{~J}$ Arnott, ${ }^{5} \mathrm{~K}$ Sanson, ${ }^{6} \mathrm{C}$ Tichanow. ${ }^{1}$ School of Health, University of Central Lancashire, Preston, UK; ${ }^{2}$ School of Health Sciences, University of Tasmania, Hobart, Australia; ${ }^{3}$ School of Health Care Practice, Auckland University of Technology, Auckland, New Zealand; ${ }^{4}$ Evidence-Based Practice Research Centre, Edge Hill University, Ormskirk, UK; ${ }^{5}$ Paediatrics, Starship Children's Health, Auckland, New Zealand; ${ }^{6}$ Paediatrics, Royal Hobart Hospital, Hobart, Australia

\subsection{6/archdischild-2014-307384.1574}

Background and aims Engaging children in research about their lives is an essential component of providing excellent health care services. Utilising participatory, visual/arts-based approaches such as photo-elicitation (PE) can extend opportunities for children to reflect on and talk about their lives. This paper aims to explore the use of, benefits and issues associated with using PE with children.

Methods PE is a participatory, qualitative method that does not rely on high levels of verbal or written literacy and which creates equitable conditions for children's engagement in research. Within a broad brief, children are asked to take topic-related photos. Apart from safety/privacy related guidance about where it might not be appropriate to take photographs, the children are free to take any image that has meaning to them. The children then select the images they wish to discuss and the researcher literally has to 'follow' the children's data and adopt a flexible approach to the conversational interview.

Results Reflecting on our experience with PE we note how the quality of discussion is enhanced and intriguing and unexpected insights into children's lives are revealed. What children choose to photograph or omit can create interesting tensions; these and other lessons will be shared along with exemplar photographs and stories.

Conclusions Although PE provides considerable opportunities and benefits, it is challenging research to be part of and requires skilled researchers to ensure children are safe during research engagement and that the data provides a robust depth of insight into their lives.

\section{PO-0955 CLOSING THE LOOP - SUCCESSFUL IMPLEMENTATION OF AUDIT RECOMMENDATIONS IN A REGIONAL DIABETES CENTRE}

S Glackin, 0 Neylon, S Molloy. Paediatric Department, Sligo Regional Hospital, Co. Sligo, Ireland

\subsection{6/archdischild-2014-307384.1575}

Background A previous audit was performed in 2011 by the Paediatric Diabetes department in Sligo Regional Hospital which examined practices, results and key care processes at annual review and compared them to International Standards $(1,2)$. This resulted in several recommendations aimed to improve metabolic control within the cohort.

Objectives The objectives of this audit were to compare HbA1c levels in 2013 to those in 2011 and to International Standards $(3,4,5)$, to investigate if the previous recommendations had been implemented and to investigate the proportion of patients with secondary complications.

Methods All paediatric patients with diabetes who had an annual review scheduled during 2013 in our centre were 